\title{
PENGEMBANGAN MEDIA PROMOSI TERINTEGRASI DAN MANAJEMEN EVENT DESA BUNTU, KECAMATAN KEJAJAR, KABUPATEN WONOSOBO
}

\author{
Stacia Reviany Mege \\ Sekolah Vokasi, Universitas Diponegoro \\ Email: staciareviany@live.undip.ac.id
}

\begin{abstract}
Buntu Village, a small village located in Kejajar Sub-district, Wonosobo Regency. For more than 10 years, the village has been the trusted by many education institutions to be a place for their students to experience living in the village. However, the village itself receives little concern by the government. The purpose of this paper is to maximize the potential of the human resources by sharing knowledge and practical application of event management, and increase the promotion of the village with integrated social media promotion. The method used in this study is consist of four steps, which are in depth interview and observation, socialization and recruitment, focus group discussion, and lastly media promotion and event management training. The result of this study is the formation of a group of local villagers with the motivation to promote Buntu Village. By receiving the training, the group of villagers is aimed to improve the management of "live in" event and also able to integrate the promotion in different social media platform.
\end{abstract}

Keywords: Event management, social media promotion, destination branding 


\section{PENDAHULUAN}

Kabupaten Wonosobo merupakan salah satu kabupaten di Provinsi Jawa Tengah yang kaya akan berbagai macam adat istiadat, destinasi wisata, kekayaan alam, dan juga keberagaman penduduk. Di Kabupaten Wonosobo, sebagaimana kabupaten lainnya, juga mengembangkan Desa Wisata. Terdapat tiga jenis desa wisata yakni desa wisata unggulan, desa wisata lestari, dan desa wisata rintisan. Salah satu yang paling terkenal adalah Gerbang Dewa, di Desa Giyanti, Kec. Selomero dan juga Cebong Sikunir di Desa Sembungan Kec. Kejajar. Terdapat total 10 desa wisata unggulan (Dinparbud Wonosobo a, 2018), 6 desa wisata lestari (Dinparbud Wonosobo b, 2018), dan dan 12 desa wisata rintisan (Dinparbud Wonosobo c, 2018).

Desa Buntu,yang terdapat di Kecamatan Kejajar, Kabupaten Wonosobo tidak termasuk kedalam salah satu dari desa wisata yang dikembangkan pemerintah Kabupaten Wonosobo. Dampaknya dapat dirasakan pada berbagai aspek, contohnya perekonomian masyarakat di Desa Buntu masih kurang berkembang dibandingkan masyarakat di desa wisata lain. Selain itu, Desa Buntu mendapatkan prioritas yang lebih rendah dalam hal pembangunan infrastruktur jalan desa, serta kurang berkembangnya sumber daya manusia.

Seperti pada desa wisata yang lain, place branding atau destination branding itu sangat mendukung menciptakan keunikan dari suatu lokasi atau desa dan akan menumbuhkan kenangan khusus tentang tempat tersebut (Blain, Levy, \& Ritchie, 2005). Tidak hanya di Jawa Tengah, desadesa di provinsi lain juga sudah mulai dikembangkan, baik oleh pemerintah, swasta maupun universitas, contohnya Kampung Naga di Jawa Barat (Satya \& Kuraesin, 2015). Oleh karena itu, Desa Buntu perlu menemukan sendiri keunikannya dan menjadikan itu sebagai nilai jual sehingga akan mengundang banyak turis baik lokal maupun internasional untuk berkunjung ke desa tersebut (Foroudi, Gupta, Kitchen, Foroudi, \& Nguyen, 2016).

Seunik apapun karakteristik yang dimiliki oleh suatu tempat, namun tetap dibutuhkan pengelolaan media promosi yang baik. Perkembangan zaman merubah tindakan wisatawan, termasuk didalamnya tindakan yang dilakukan untuk mendapatkan informasi dan pengambilan keputusan, dimana pada saat ini lebih cenderung mengandalkan internet dan teknologi (Andrlic \& De Alwis, 2016).

Media sosial merupakan website yang menghubungkan sahabat, keluarga, rekan kerja dan lain sebagainya. Dalam beberapa tahun terakhir ini, media sosial menjadi fokus dari para pemasar karena menyediakan kesempatan untuk melakukan promosi baik secara gratis maupun berbayar (Zarella, 2010). Poin penting dari melakukan promosi melalui media sosial adalah harus adanya keselarasan informasi antara media yang satu dengan media yang lain sehingga tidak terjadi kesalahan informasi (Duralia, 2018).

Selain membutuhkan promosi yang terintegrasi untuk memperkenalkan kepada masyarakat keunikan Desa Buntu, maka diperlukan juga pemahaman dan penguasaan event management sebagai hasil atau luaran dari aktivitas manajemen dan promosi yang sudah dilakukan (Müller-Seitz \& Schüßler, 2013).

\section{METODE PELAKSANAAN}

Kegiatan pengabdian kepada masyarakat ini dilakukan dalam beberapa tahapan yakni sebagai berikut. Tahapan yang pertama (1) adalah in depth interview dan observasi. Dilanjutkan dengan tahapan kedua (2) yakni sosialisasi dan perekrutan. Tahapan yang ketiga (3) adalah focus group discussion. Dan tahapan yang terakhir (4) adalah pelatihan pembuatan dan pengelolaan media promosi terintegrasi dan manajemen event.

Pada tahapan pertama yakni in depth interview dengan kepala desa dan perangkat desa. Tahapan ini dilakukan sebagai langkah pertama untuk mendapatkan informasi dasar tentang Desa Buntu itu sendiri, mulai dari luas wilayah desa, jumlah penduduk, usia penduduk, pekerjaan, komoditas yang dihasilkan, keberagaman agama, jumlah tempat ibadah, kegiatan kebudayaan dan keagamaan, dan informasi demografis lainnya. Selain informasi geografis, 
demografis, dan sebagainya, ditanyakan lagi secara mendalam mengenai kebudayaan di dalam desa, programprogram yang pernah dilaksanakan sebelumnya baik oleh pihak desa, maupun pihak pemerintah Kabupaten, serta keunikan yang dimiliki oleh desa, penduduk, ataupun alam di desa itu. Observasi dilaksanakan sebanyak dua kali sebelum pelaksanaan kegiatan untuk melihat dan mempelajari secara langsung bagaimana situasi di desa seperti yang sudah dipaparkan dalam interview.

Setelah tahapan interview dan obervasi, ditemukan keunikan yang ingin ditonjolkan oleh penduduk Desa Buntu. Untuk itu diperlukanlah sebuah tim khusus yang bertanggung jawab akan hal ini. Oleh karena itu diperlukan tahapan sosialisasi dan perekrutan. Tahapan selanjutnya yakni melakukan Focus Group Discussion bersama dengan tim yang sudah direkrut mengenai apa yang telah dilakukan, dan ingin dilakukan serta diharapkan dari pelatihan ini.

Tahapan pelatihan pembuatan media promosi adalah tahapan terakhir dalam pelatihan ini yang bertujuan untuk menciptakan media promosi yang profesional dan dikelola secara profesional serta bagaimana mengelola event secara profesional.

\section{HASIL DAN PEMBAHASAN}

Hasil dari setiap tahapan kegiatan dalam pengabdian kepada masyarakat ini mempengaruhi tahapan selanjutnya. Sehingga hasil dan pembahasan akan dijelaskan secara bertahap.

Pada tahapan pertama yakni in depth interview dengan kepala desa dan perangkat desa, diperoleh informasi sebagaimana tertera pada tabel dibawah ini.

Tabel 1. Data Desa Buntu

\begin{tabular}{l|l}
\hline Informasi & Keterangan \\
\hline Jumlah Penduduk & \\
-Laki-laki & 1407 orang \\
-Perempuan & 1336 orang \\
\hline Pengangguran & \\
-Jumlah angkatan kerja & 1458 orang \\
(18-56) & 237 orang \\
-Ibu rumah tangga & 897 orang \\
-Bekerja penuh & 232 orang \\
-Bekerja tidak tentu & \\
\hline
\end{tabular}

\begin{tabular}{l|l}
\hline Hasil produksi pertanian & \\
\& Perkebunan & \\
-Kentang & 10 ton/Ha \\
-Kubis & 20 ton/Ha \\
-Cabe & 15 ton/Ha \\
-Wortel & 14 ton/Ha \\
-Tembakau & 3 ton/Ha \\
\hline Subsektor Pedagang & 4 unit \\
Eceran & \\
\hline Subsektor Jasa & 2 unit \\
Pemerintahan & \\
\hline Struktur Mata & \\
Pencaharian & 29 orang \\
-Petani & 153 orang \\
-Buruh tani & 1068 orang \\
-Pemilik usaha tani & 26 orang \\
-Tukang kayu & 13 orang \\
-Tukang batu & 10 orang \\
-Pemilik usaha jasa & 11 orang \\
transport & \\
-Pegawai negeri sipil & \\
\hline Tingkat Pendidikan & \\
-Tamat SD & 1209 orang \\
-Tamat SMP & 351 orang \\
-Tamat SMA & 122 orang \\
-Tamat D3 & 4 orang \\
-Tamat S1 & 16 orang \\
\hline $\begin{array}{l}\text { Jumlah masyarakat yang } \\
\text { terlibat dalam } \\
\text { pembangunan fisik }\end{array}$ & $100 \%$ \\
\hline Sumber: hast & \\
\hline
\end{tabular}

(Sumber: hasil olahan penulis, 2018)

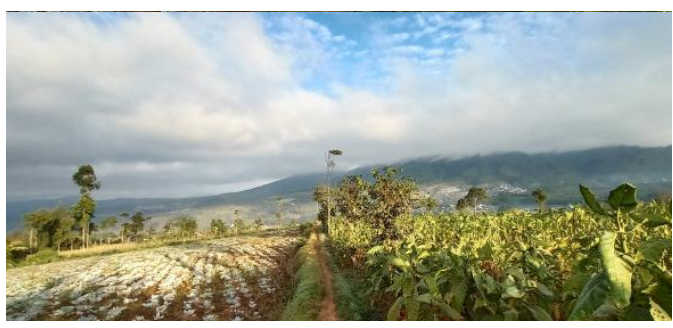

Gambar 1. Pertanian Desa Buntu

Informasi yang berhasil dikumpulkan tersebut cukup jelas memperlihatkan bahwa sebagian besar penduduk berprofesi di bidang pertanian dan perkebunan. Bahkan hasil observasi lapangan secara jelas memperlihatkan bahwa terdapat lahan pertanian dan perkebunan yang luas, mencapai sekitar 234 Ha, dengan didominasi oleh perkebunan tembakau (154 Ha). Sebaliknya dalam sektor jasa, hanya terdapat sebagian kecil dari masyarakat yang memiliki mata pencaharian di sektor tersebut. 
Fokus dari wawancara kepada perangkat desa adalah untuk menemukan keunikan apa yang ingin ditonjolkan dari Desa Buntu ini.

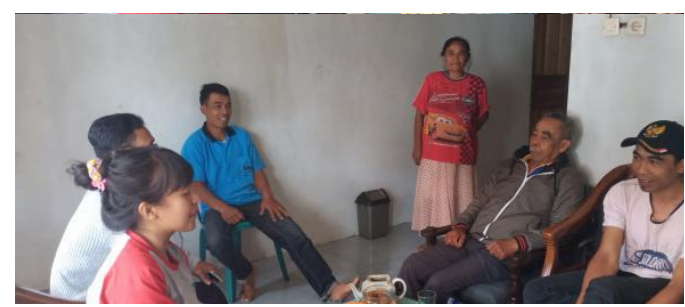

Gambar 2. Kegiatan Interview

Dari hasil wawancara dengan aparatur desa, ditemukan satu kegiatan yang dapat dikategorikan sebagai penyedia jasa swasta atau jasa hiburan yang sudah berjalan selama lebih dari 10 tahun. Sejak tahun 2006, Desa Buntu menjadi lokasi pelaksanaan Live In dari sekolah-sekolah (SLTP/SMA) baik dari Jawa Tengah maupun luar Jateng. Kegiatan Live In memiliki konsep yang menarik, yakni para peserta belajar untuk hidup seperti warga desa, melakukan aktivitas bercocok tanam, mengolah kopi secara tradisional, dan mempelajari kebudayaan yang ada di Desa Buntu. Dalam 1 tahun, bisa terdapat 3-4 kegiatan serupa. Seluruh warga desa berpartisipasi aktif dalam kegiatan ini. Bahkan warga desa secara kolektif memiliki aset desa seperti tenda, kursi plastik, TV, LCD proyektor, mixer dan speaker sebagai hasil dari kegiatan tersebut. Menurut penyataan dari informan, warga juga mendapatkan keuntungan secara finansial dari kegiatan ini. Dari hasil wawancara dan observasi juga diketahui bahwa kegiatan Live In ini masih dikelola secara gotong royong dan kurang profesional serta tidak adanya struktur organisasi yang jelas.

Hal menarik lain yang ingin ditonjolkan adalah toleransi beragama. Penduduk Desa Buntu terdiri dari pemeluk empat agama yang berbeda, Kristen Protestan, Islam, Katolik, dan Budha. Rumah ibadah dari masing-masing agama pun berdekatan dengan rumah penduduk dan berdasarkan data dari kantor Desa, tidak pernah terjadi konflik yang melibatkan SARA di dalam desa tersebut. Toleransi antar umat beragama di Desa Buntu ini diangkat ke tingkat Nasional oleh
Bupati saat itu. Daya tarik ini juga yang mendorong banyak dilaksanakannya kegiatan Live in sejak tahun 2016. Kepada desa serta aparatur desa mengharapkan agar Live in bisa dikelola secara lebih profesional, sehingga manfaat yang diberikan kepada warga bisa lebih diraskan.

Tahapan kedua. Sosialisasi dilaksanakan di balai desa dengan melibatkan aparatur desa dan masyarakat. Tujuan dari tahapan kedua ini adalah agar masyarakat secara umum memahami pentingnya pengelolaan event secara baik dan pentingnya media promosi yang terintegrasi sehingga keunikan yang dimiliki Desa Buntu bisa diketahui secara lebih luas. Proses perekrutan dilaksanakan secara terbuka, yakni setiap warga yang berkeinginan untuk menjadi tim pengelola tidak melakukan karena adanya paksaan dari aparatur desa. Hasilnya, diperoleh empat orang pemuda (kaum milenial) usia 18-24 tahun yang secara sukarela dan antusias menjadi bagian dari tim, ditambah satu orang koordinator (usia 40 tahun) yang merupakan penanggung jawab dari kegiatan Live in yang selama ini sudah berjalan.

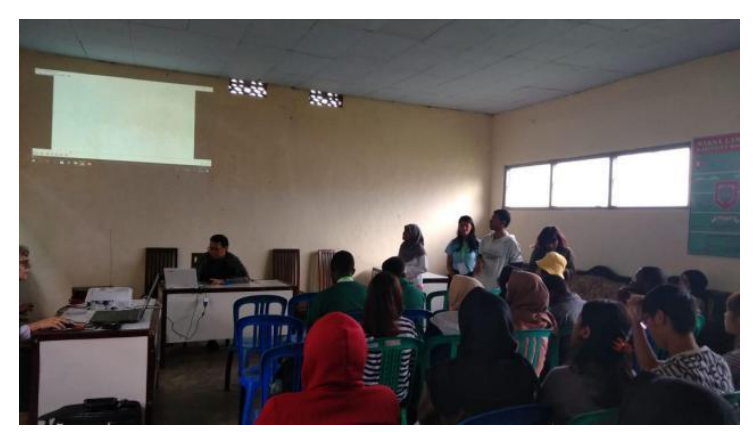

Gambar 2. Kegiatan Sosialisasi

Tahapan ketiga. Focus group discussion dilakukan untuk mengetahui apa yang sudah dilakukan, ingin dilakukan dan apa yang diharapkan dari pelatihan ini. Hasil yang diperoleh adalah sebagai berikut:

Tabel 2. Ringkasan Hasil FGD 


\section{Hasil FGD \\ Pemanfaatan media sosial: \\ - Setiap anggota tim pengguna aktif instagram \\ - Setiap anggota tim pernah (lebih dari 2 kali) mengunggah foto Desa Buntu \\ - Koordinator memiliki koleksi foto dan video kegiatan Live in sebelumnya namun tidak punya media untuk diunggah \\ - Salah seorang anggota memiliki akun youtube dan pernah mengunggah video kegiatan live in di akun pribadinya tersebut}

Pengelolaan event live in:

- Berpengalaman lebih dari 10 tahun mengelola kegiatan live in di Desa

Buntu

- Tidak ada struktur organisasi dalam pengelolaan live in

- Memiliki database sekolah-sekolah yang pernah melaksanakan live in $\mathrm{di}$ Desa Buntu

- Memiliki aset tetap hasil kegiatan live in sebelumnya

- Tidak memiliki kelengkapan suratsurat

- Tidak ada media promosi, dan tidak melakukan promosi.

- Tidak menetapkan harga standar untuk kegiatan

Rencana kedepan :

- Membuat struktur organisasi pengelola kegiatan live in Desa Buntu

- Merapikan database pelanggan

- Membuat database aset yang sudah dimiliki

- Menetapkan standar harga untuk

kegiatan

- Membuat email khusus untuk Desa

Buntu

- Membuat akun media sosial Instagram

Bisnis, dan Laman Facebook yang terintegrasi satu sama lain

- Membuat akun youtube Desa Buntu

- Menyusun daftar kegiatan kebudayaan,

keagamaan sepanjang tahun

- Membuat website Desa Buntu

- Mendesain branding Desa Buntu

(Sumber: hasil olahan penulis, 2019)
Dapat dilihat pada tabel diatas bahwa focus group discussion yang digagas dan dipandu oleh penulis menghasilkan suatu rencana untuk pengembangan pengelolaan event secara profesional dan juga mempromosikan Desa Buntu melalui media komunikasi yang terintegrasi.

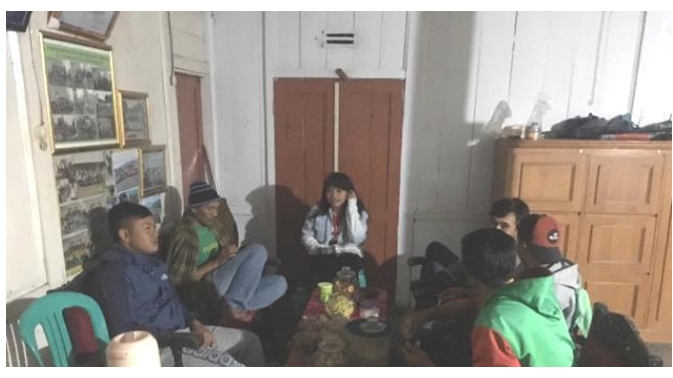

Gambar 2. Focus Group Discussion

Tahapan keempat. Tahapan terakhir dalam kegiatan pengabdian kepada masyarakat ini adalah tahapan dimana penulis memberikan bimbingan untuk manajemen event dan juga media promosi.

Pelatihan manajemen event dilakukan dengan memberikan modul dan pedoman bagaimana mengelola event dengan baik. Materi yang diberikan terkait pengelolaan event dapat dilihat pada tabel di bawah ini.

\section{Tabel 3. Materi Manajemen Event}

\begin{tabular}{l|l}
\hline Sesi & Materi \\
\hline Sesi 1 & Manajemen Event \\
\hline Sesi 2 & Seputar Event Organizer \\
\hline Sesi 3 & $\begin{array}{l}\text { Perencanaan } \\
\text { penyelenggaraan event }\end{array}$ \\
\hline Sesi 4 & Pembiayaan event \\
\hline Sesi 5 & Publikasi dan promosi event \\
\hline Sesi 6 & Legalitas event \\
\hline
\end{tabular}

(Sumber: Kusuma, 2016)

Pada pemaparan materi ini, peserta lebih berfokus kepada perencanaan penyelenggaraan event, serta publikasi dan promosi event. Pemateri menghimbau tentang pentingnya mengatur tentang pembiayaan event, namun peserta kurang sependapat. Hal itu karena berdasarkan pengalaman sebelumnya, sekolah atau instansi yang datang ke Desa Buntu sudah menyiapakan mengenai pembiayaan, sehingga peserta merasa kurang penting untuk memahami bagaimana membuat 
anggaran. Namun peserta setuju untuk menetapkan standar harga untuk kegiatan yang bisa dilakukan di dalam desa, dengan tujuan untuk kesejahteraan bersama. Legalitas tim sebagai penyelenggara event sendiri pun masih mendapatkan prioritas yang rendah. Hal tersebut tercermin juga dari tidak adanya NPWP pribadi dari masing-masing anggota tim (yang sudah bekerja). Sehingga mengembangkan urusan legalitas akan dilakukan kemudian, dengan meminta kerja sama dari pihak kantor desa. Materi selanjutnya yang dipaparkan adalah mengenai media promosi. Topik ini sangat penting untuk dibahas, karena tim tersebut diharapkan bisa melakukan promosi untuk Desa Buntu dan kegiatan live in yang menjadi salah satu daya tarik dari desa ini.

\section{Tabel 4. Materi Media Promosi}

\begin{tabular}{l|l}
\hline Sesi & Materi \\
\hline Sesi 1 & Jenis-jenis media promosi \\
\hline Sesi 2 & $\begin{array}{l}\text { Instagram Bisnis, Akun } \\
\text { Youtube, Laman Facebook }\end{array}$ \\
\hline Sesi 3 & $\begin{array}{l}\text { Mempersiapkan biografi } \\
\text { untuk akun medias sosial }\end{array}$ \\
\hline Sesi 4 & $\begin{array}{l}\text { Mencari dan meningatkan } \\
\text { jumlah follower }\end{array}$ \\
\hline Sesi 5 & $\begin{array}{l}\text { Membuat postingan yang } \\
\text { menarik perhatian konsumen }\end{array}$ \\
\hline Sesi 6 & $\begin{array}{l}\text { Memanfaatkan IG dan FB } \\
\text { story }\end{array}$ \\
\hline Sesi 7 & Membuat akun youtube \\
\hline Sesi 8 & $\begin{array}{l}\text { Membuat promosi yang } \\
\text { terintegrasi }\end{array}$ \\
\hline
\end{tabular}

(Sumber: hasil olahan penulis, 2019)

Materi pelatihan pada pengabdian kali ini lebih berfokus kepada media promosi lewat internet atau secara spesifik, media sosial yang saat ini paling sering digunakan yakni instagram, facebook, dan youtube. Selain itu, media-media ini adalah yang sudah bisa digunakan oleh anggota tim tanpa membutuhkan jangka waktu lama. Sehingga praktik yang diajarkan lebih kepada panduan untuk membuat akun media sosial lebih profesional, serta bagaimana cara membuat unggahan dapat diakses banyak orang.

Branding Desa Buntu merupakan elemen yang sangat penting karena dengan adanya destination branding yang unik, maka Desa Buntu akan lebih dikenal.
Namun, pembuatan branding tidak dimasukan kedalam pelatihan kali ini karena beberapa alasan. Pertama, pembuatan branding suatu desa, kota dan tempat lain, tidak dapat diputuskan dalam waktu yang singkat. Dibutuhkan kajian mendalam dan diskusi dengan berbagai pihak khususnya penduduk desa, tentang status yang akan menjadi identitas mereka. Alasan kedua, yakni berhubungan dengan mendesain logo dari Desa Buntu dimana sekali lagi membutuhkan kajian mendalam agar logo tersebut bisa mewakili karakteristik desa. Alasan terakhir adalah karena anggota tim tidak memiliki kapasitas untuk merancang brand. Pembuatan website akan dilaksanakan berbarengan dengan pembuatan brand.

Hasil dari pelatihan pada sesi kali ini adalah anggota tim mampu membuat instagram bisnis, laman facebook, dan akun youtube, dan mampu mengelolanya secara profesional. Selain itu peserta atau anggota tim juga telah memahami pentingnya promosi yang terintegrasi dan bagaimana mengintegrasikan konten yang diunggah.

\section{KESIMPULAN}

Desa Buntu memiliki potensi yang dapat dikembangkan untuk menjadikannya setara dengan desa wisata di Kabupaten Wonosobo, Jawa Tengah. Salah satu potensi yang dimiliki yaitu selama lebih dari 10 tahun menjadi tempat dilaksanakannya kegiatan live in. Untuk mengembangkan potensi tersebut, maka diperlukan pemahaman manajemen event yang baik terlebih khusus untuk tim yang sudah terbentuk. Disamping itu, oleh karena dibatasi pada waktu dan kemampuan teknis, maka tim Desa Buntu dibekali dengan pengetahuan dan praktek dasar untuk menggunakan media sosial instagram, facebook, dan youtube. Ketiga media itu, oleh para peserta pelatihan (tim Desa Buntu) dirasa cukup dan mampu mereka pelajari dengan mudah. Dengan demikian, peserta yang sudah dibekali dengan pengetahuan dan praktikum manajemen event dan promosi melalui media sosial, dinilai dapat mengkombinasikan keduanya untuk meningkatkan nilai jual Desa Buntu di kalangan wisatawan. 


\section{REFERENSI}

Andrlic, B. dan De Alwis, A. Chamaru. (2016). Social Media in Destination Marketing. International Journal of Management and Applied Science.

Blain, C., Levy, S. E., Ritchie, J. R. B. (2005). Destination branding:
insights and practices from destination management organizations. Journal of Travel Research, 40, 329. doi: $10.1177 / 0047287505274646$

Dinas Pariwisata dan Kebudayaan Kabupaten Wonosobo a. 2018. Desa Wisata Unggulan.https://disparbud.wonos obokab.

go.id/post/detail/1031698/Desa W isata Unggulan.HTML.Diakses tanggal 21 November 2019.

Dinas Pariwisata dan Kebudayaan Kabupaten Wonosobo b. 2018. Desa Wisata Lestari. https://disparbud.wonosobokab.go. id/post

/detail/1031699/Desa_Wisata_Lest ari.HT ML.Diakses tanggal 21 November 2019.

Dinas Pariwisata dan Kebudayaan Kabupaten Wonosobo c. 2018. Desa Wisata Rintisan. https://disparbud.wonosobokab.go. id/post

/detail/1031700/Desa_Wisata_Rint isan.H TML.Diakses tanggal 21 November 2019.

Duralia, O. (2018). Integrated Marketing Communication and its impact on Consumer Behavior. Studies in Business and Economics, 13(2).

Foroudi, P., Gupta, S., Kitchen, P., Foroudi, M. M., and Nguyen, B. (2016) A framework of place branding, place image, and place reputation: antecedents and moderators. Qualitative Market Research: An International Journal, Vol. 19, No. 2, pp. 241-264.

Kusuma, Rr. C. S. D. 2016. Modul Manajemen Event. Universitas Negeri Yogyakarta.

Müller-Seitz, G. \& Schüßler, E. (2013). From event management to managing events. A process perspective on organized and unexpected field-level events. Managementforschung, 23, 193226.

https://www.researchgate.net/publi cation/ 259117550 From Event Manage ment $t$ o Managing Events 